\title{
Metabolome analysis-based design and engineering of a metabolic pathway in Corynebacterium glutamicum to match rates of simultaneous utilization of D-glucose and L-arabinose
}

\author{
Hideo Kawaguchi ${ }^{1}$, Kumiko Yoshihara ${ }^{1}$, Kiyotaka Y. Hara ${ }^{1,2}$, Tomohisa Hasunuma ${ }^{1}$, Chiaki Ogino ${ }^{3}$
} and Akihiko Kondo 1,3,4*0

\begin{abstract}
Background: L-Arabinose is the second most abundant component of hemicellulose in lignocellulosic biomass, next to D-xylose. However, few microorganisms are capable of utilizing pentoses, and catabolic genes and operons enabling bacterial utilization of pentoses are typically subject to carbon catabolite repression by more-preferred carbon sources, such as D-glucose, leading to a preferential utilization of D-glucose over pentoses. In order to simultaneously utilize both D-glucose and L-arabinose at the same rate, a modified metabolic pathway was rationally designed based on metabolome analysis.

Results: Corynebacterium glutamicum ATCC 31831 utilized D-glucose and L-arabinose simultaneously at a low concentration (3.6 g/L each) but preferentially utilized D-glucose over L-arabinose at a high concentration ( $15 \mathrm{~g} / \mathrm{L} \mathrm{each),}$ although L-arabinose and D-glucose were consumed at comparable rates in the absence of the second carbon source. Metabolome analysis revealed that phosphofructokinase and pyruvate kinase were major bottlenecks for D-glucose and L-arabinose metabolism, respectively. Based on the results of metabolome analysis, a metabolic pathway was engineered by overexpressing pyruvate kinase in combination with deletion of araR, which encodes a repressor of L-arabinose uptake and catabolism. The recombinant strain utilized high concentrations of D-glucose and L-arabinose (15 g/L each) at the same consumption rate. During simultaneous utilization of both carbon sources at high concentrations, intracellular levels of phosphoenolpyruvate declined and acetyl-CoA levels increased significantly as compared with the wild-type strain that preferentially utilized D-glucose. These results suggest that overexpression of pyruvate kinase in the araR deletion strain increased the specific consumption rate of L-arabinose and that citrate synthase activity becomes a new bottleneck in the engineered pathway during the simultaneous utilization of D-glucose and L-arabinose.
\end{abstract}

Conclusions: Metabolome analysis identified potential bottlenecks in D-glucose and L-arabinose metabolism and was then applied to the following rational metabolic engineering. Manipulation of only two genes enabled simultaneous utilization of D-glucose and L-arabinose at the same rate in metabolically engineered C. glutamicum. This is the

\footnotetext{
*Correspondence: akondo@kobe-u.ac.jp

${ }^{1}$ Graduate School of Science, Technology and Innovation, Kobe

University, 1-1 Rokkodai, Nada, Kobe 657-8501, Japan

Full list of author information is available at the end of the article
} 
first report of rational metabolic design and engineering for simultaneous hexose and pentose utilization without inactivating the phosphotransferase system.

Keywords: Corynebacterium glutamicum, Simultaneous utilization, L-Arabinose, Metabolic engineering, Metabolome analysis

\section{Background}

L-Arabinose is the second most abundant component of hemicellulose in lignocellulosic biomass, next to D-xylose. Lignocellulosic feedstocks contain cellulose and hemicellulose (14.3-49.9 and $8.8-22.4 \%$, respectively) [1]. Hydrolysis of the lignocellulosic feedstocks yields D-glucose, D-xylose, L-arabinose, and other minor sugar. In the hydrolysates, D-xylose (12-23\%) and D-glucose $(2-24 \%)$ are typically abundant components, followed by L-arabinose (2-6\%), although the composition of these monosaccharides depends on feedstocks and hydrolysis conditions [2-4]. In some cases, L-arabinose-rich hydrolysate was also reported. For instance, corn fiber hydrolysate consists of $22 \% \mathrm{~L}$-arabinose $38 \% \mathrm{D}$-glucose, and $30 \%$ xylose [5], and sugar beet pulp hydrolysate consists of $78 \% \mathrm{~L}$-arabinose, $3.9 \% \mathrm{D}$-glucose, and $1.4 \% \mathrm{D}$-xylose [6]. Thus, the capability of metabolizing these pentoses and D-glucose simultaneously is important for optimal microbial fermentation to more efficiently utilize carbohydrates contained in lignocellulosic feedstocks, as the hydrolysates are predominantly composed of hexose(s) and pentose(s) [7]. However, few microorganisms are capable of utilizing pentoses for bio-based production.

Escherichia coli expresses specific transporters and metabolic enzymes that enable the bacteria to utilize both D-xylose and L-arabinose $[8,9]$. To take up L-arabinose, E. coli expresses two transporters, a low-affinity $\mathrm{H}^{+}$symporter and a high-affinity adenosine $5^{\prime}$-triphosphate (ATP)-dependent transporter encoded by araE and $\operatorname{araFGH}$, respectively $[10,11]$. Once taken up by cells, L-arabinose is converted to L-ribulose, L-ribulose 5-phosphate, and D-xylulose 5-phosphate (X5P) in reactions catalyzed by L-arabinose isomerase (encoded by $\operatorname{araA}$ ), L-ribulokinase ( $\operatorname{ara} B$ ), and L-ribulose-5-phosphate 4-epimerase ( $a r a D)$, respectively [9]. X5P then enters the non-oxidative pentose phosphate pathway (PPP) (Fig. 1).

Catabolic genes and operons enabling bacterial utilization of pentoses are typically subject to carbon catabolite repression (CCR) by more-preferred carbon sources, such as D-glucose [12]. This distinct regulatory system hinders the simultaneous utilization of D-glucose and pentoses such as $\mathrm{D}$-xylose and L-arabinose. Considerable research has focused on inactivation of the phosphotransferase system (PTS) that regulates glucose uptake and metabolism [13] to avoid CCR of pentose metabolism, particularly in E. coli [14]. However, inactivation of the PTS markedly reduces D-glucose utilization [15]. After PTS inactivation, adaptive evolution selection of $\mathrm{PTS}^{-} \mathrm{Glc}^{+}$mutants has been reported to restore D-glucose metabolism [16], however this can be negatively impacted by the accumulation of undesirable spontaneously arising mutations in the host genome. Thus, an alternative and more rational strategy is needed to develop a microbial platform for the simultaneous utilization of D-glucose and pentose(s).

Corynebacterium glutamicum is a non-pathogenic Gram-positive bacterium widely studied for the production of amino acids [17] and a variety of commodity chemicals $[18,19]$. However, unlike E. coli, C. glutamicum lacks pentose assimilation pathways [20], with the exception of strain ATCC 31831, which has a gene cluster

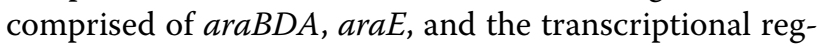
ulator encoded by araR (Fig. 1) and grows on L-arabinose as the sole carbon source [21]. Metabolic engineering of C. glutamicum to express araBAD from E. coli or $x y l A B$ enables the organism to catabolize the pentoses L-arabinose and D-xylose, respectively [22-29]. Moreover, integration of the Weimberg pathway from Caulobacter crescentus enables the efficient utilization of $\mathrm{D}$-xylose [30-32]. However, simultaneous utilization of D-glucose and pentose(s) is possible only in culture at a relatively low concentration of D-glucose [33] or in a high-cell-density reaction [27, 34], or following metabolic engineering to produce a $\mathrm{PTS}^{-}$mutant, resulting in reduced D-glucose utilization $[15,35,36]$. These limitations could be overcome by the rational design of a metabolic pathway enabling the simultaneous utilization of multiple sugars at varying proportions.

In the present study, metabolome analysis was employed to identify the bottlenecks limiting utilization of either D-glucose or $\mathrm{L}$-arabinose by $C$. glutamicum ATCC 31831. Based on this analysis, a pathway for simultaneous utilization of $\mathrm{D}$-glucose and L-arabinose was rationally designed and engineered. Elimination of the major bottleneck limiting L-arabinose metabolism enabled the simultaneous and complete utilization of D-glucose and L-arabinose at the same rate by the metabolically engineered strain, with minimal decline in D-glucose consumption. The metabolome analysis also revealed contrasting metabolic profiles of preferential and simultaneous utilization of $\mathrm{D}$-glucose and $\mathrm{L}$-arabinose. This is the first report of the application of metabolome analysis 


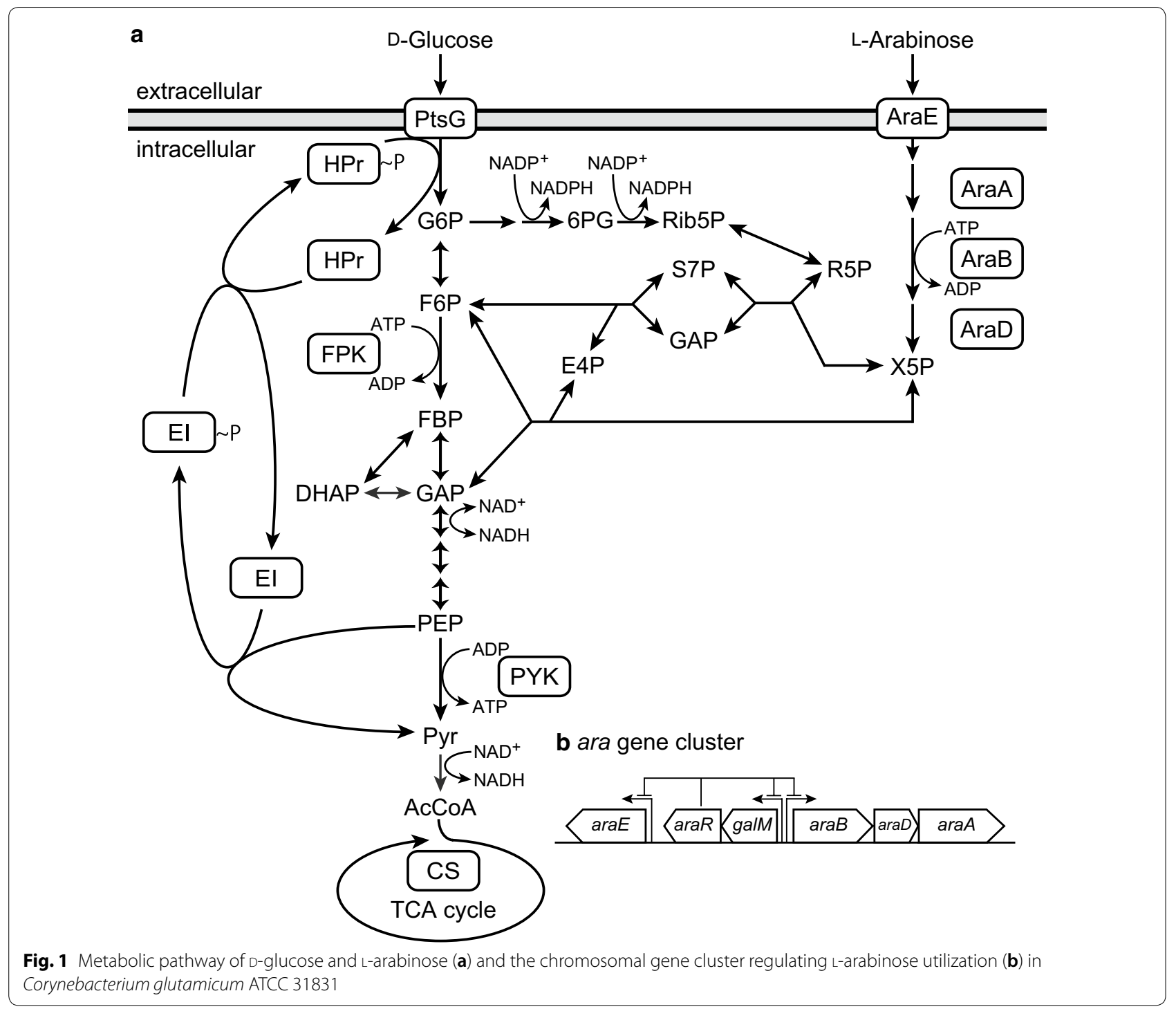

in the design and evaluation of an engineered pathway for simultaneous hexose and pentose utilization, resulting in bypass of CCR without inactivating the PTS that markedly reduces D-glucose utilization.

\section{Methods}

\section{Bacterial strains, media, cultivation conditions,} and plasmids

Bacterial strains and plasmids used in this study are listed in Table 1. For genetic manipulations, E. coli strains were grown at $37{ }^{\circ} \mathrm{C}$ in Luria-Bertani medium [37]. For precultivation of $C$. glutamicum, nutrient-rich A medium [38] supplemented with D-glucose $(40 \mathrm{~g} / \mathrm{L})$ was used, unless indicated otherwise. For cultivation of C. glutamicum, mineral salt BT medium [38] supplemented with D-glucose and L-arabinose (15 g/L each) was used, unless indicated otherwise. Broth cultures of C. glutamicum were incubated at $30{ }^{\circ} \mathrm{C}$ in $500-\mathrm{mL}$ baffled flasks with constant agitation $(180 \mathrm{rpm})$. Where appropriate, media were supplemented with kanamycin $(50 \mu \mathrm{g} / \mathrm{mL})$ for both E. coli and C. glutamicum.

\section{DNA manipulation}

All restriction endonucleases were purchased from New England Biolabs (Ipswich, MA). PrimeSTAR Max DNA Polymerase (TakaraBio, Shiga, Japan) was used in PCR to amplify DNA fragments, according to the manufacturer's instructions. PCR fragments were purified using a QIAquick PCR Purification kit (Qiagen, Hilden, Germany). Electroporation was used to transform C. glutamicum, as previously described [39], whereas E. coli was transformed using the $\mathrm{CaCl}_{2}$ procedure [37]. Plasmid 
Table 1 Strains and plasmids used in this study

\begin{tabular}{|c|c|c|}
\hline Name & Relevant characteristics & Reference or source \\
\hline \multicolumn{3}{|l|}{ Strain } \\
\hline Escherichia coli JM109 & 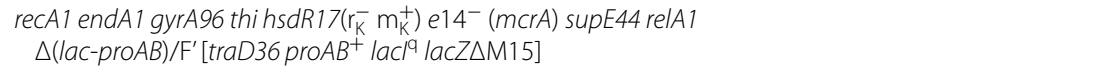 & TakaraBio \\
\hline $\begin{array}{l}\text { Corynebacterium glutami- } \\
\text { cum ATCC13032 }\end{array}$ & Type-strain of C. glutamicum & ATCC \\
\hline C. glutamicum ATCC31831 & Wild type & ATCC \\
\hline$\triangle a r a R$ & Markerless araR-deletion mutant of strain ATCC 31831 & This study \\
\hline $31831 / \mathrm{pCH}$ & C. glutamicum ATCC31831 bearing pCH & This study \\
\hline 31831/pCHpyk & C. glutamicum ATCC31831 bearing pCHpyk & This study \\
\hline$\triangle \operatorname{araR} / \mathrm{pCH}$ & $\triangle$ araR bearing $\mathrm{pCH}$ & This study \\
\hline$\triangle a r a R / p C H p y k$ & $\triangle$ araR bearing $\mathrm{pCHpyk}$ & This study \\
\hline \multicolumn{3}{|l|}{ Plasmid } \\
\hline $\mathrm{pCH}$ & $\mathrm{Km}^{r} ;$ E. coli-Corynebacterium sp. shuttle vector & {$[40]$} \\
\hline pCHgltA & $\begin{array}{l}\mathrm{Km}^{\mathrm{r}} \text {; pCH with PCR fragment containing C. glutamicum ATCC31831 gltA gene (NCgl0795) encod- } \\
\text { ing citrate synthase }\end{array}$ & \\
\hline pCHpfk & $\begin{array}{l}\mathrm{Km}^{\mathrm{r}} ; \mathrm{pCH} \text { with PCR fragment containing C. glutamicum ATCC31831 pfk gene (NCgl1202) encoding } \\
\text { phosphofructokinase }\end{array}$ & \\
\hline pCHpyk & $\begin{array}{l}\mathrm{Km}^{\mathrm{r}} ; \text { pCH with PCR fragment containing C. glutamicum ATCC31831 pyk gene (NCgl2008) encoding } \\
\text { pyruvate kinase }\end{array}$ & This study \\
\hline pK19mobsacB & $\begin{array}{l}\text { Kan', mobilizable E. coli vector for the construction of insertion and deletion mutants of C. glutami- } \\
\text { cum (oriV, sacB, lacZa) }\end{array}$ & ATCC \\
\hline pK19mobsac- $\triangle a r a R$ & Kan', pK19mobsacB with the deletion construct for araR of C. glutamicum ATCC31831 & This study \\
\hline
\end{tabular}

DNA was isolated from E. coli as previously described [22].

\section{Construction of recombinant $C$. glutamicum strains}

The E. coli-C. glutamicum shuttle vector pCH [40] was used to overexpress gltA (NCgl0795), pfk (NCgl1202), and pyk (NCgl2008) genes encoding C. glutamicum ATCC 13032 citrate synthase, 6-phosphofructokinase, and pyruvate kinase, respectively. DNA fragments encoding the gltA and pyk genes were amplified by PCR using the C. glutamicum ATCC 13032 genome as the template and oligonucleotide primer pairs (primers 1 and 2 and primers 3 and 4, respectively; Table 2). The resulting two PCR amplicons were digested with BamHI and Pst and subsequently ligated into Bam $\mathrm{HI}$ and PstI-digested $\mathrm{pCH}$ DNA, generating the constructs $\mathrm{pCH}$ gltA and pCHpyk, respectively (Table 1). Likewise, a DNA fragment encoding the $p f k$ gene was amplified by PCR using the C. glutamicum ATCC 13032 genome as the template and oligonucleotide primers 5 and 6. The resulting PCR amplicons were digested with $\mathrm{BamHI}$ and $S a c \mathrm{I}$ and subsequently ligated into $\mathrm{BamHI}$ and SacI-digested $\mathrm{pCH}$ DNA, generating the construct pCHpfk (Table 1).

Strains of C. glutamicum with a deleted araR repressor gene were constructed as previously described [41]. Regions upstream and downstream of $\operatorname{araR}$ were amplified by PCR using the C. glutamicum ATCC 31831 genome as the template and oligonucleotide primer pairs 7 and 8 and 9 and 10, respectively (Table 2). The PCR-amplified upstream and downstream fragments were digested with the restriction enzyme pairs Pst I and HindIII and Pst I and EcoRI, respectively. The Pst and EcoRI-digested downstream fragment was ligated into Pst I and EcoRI-digested pK19mobsacB (American Type Culture Collection, Manassas, VA). The resulting plasmid was digested with PstI and HindIII and then ligated with the PstI and EcoRI-digested upstream fragment, generating the construct $\mathrm{pK} 19 \mathrm{mobsac}-\Delta a r a R$ (Table 1). Gene deletion was confirmed by PCR using oligonucleotide primers 7 and 10 .

\section{Sugar utilization by C. glutamicum strains}

All wild-type and recombinant C. glutamicum strains were grown aerobically at $30{ }^{\circ} \mathrm{C}$ to late log phase in A medium, and then harvested by centrifugation $\left(7000 \times g, 4{ }^{\circ} \mathrm{C}, 10 \mathrm{~min}\right)$. The cell pellets were subsequently washed with mineral salt BT medium. After the second wash, cells were inoculated into $100 \mathrm{~mL}$ of BT medium containing an appropriate concentration of sugars to an optical density at $600 \mathrm{~nm}\left(\mathrm{OD}_{600}\right)$ of 0.2 . The resulting culture was incubated at $30{ }^{\circ} \mathrm{C}$ in a 500 $\mathrm{mL}$ baffled flask with constant agitation $(170 \mathrm{rpm})$. 
Table 2 Oligonucleotides used in this study

\begin{tabular}{|c|c|c|c|}
\hline Name & Target gene & Sequence $\left(5^{\prime}-3^{\prime}\right)$ & Cohesive ends ${ }^{a}$ \\
\hline Primer 1 & $g / t A$ & CTCTGGATCCGACTACTTCCGTAATCCGGA & $\mathrm{BamHI}$ \\
\hline Primer 2 & $g / t A$ & CTCTCTGCAGCCGGTAGCTCAATCTGTGGC & Pstl \\
\hline Primer 3 & pyk & CTCTGGATCCATGGTAGTACCTGTGGCTTG & $\mathrm{BamHI}$ \\
\hline Primer 4 & pyk & CTCTCTGCAGATGCTCTGCTCAAGAAGTGC & Pstl \\
\hline Primer 5 & $p f k$ & CTCTGGATCCATAAGATGGTCAGAGACAGT & $\mathrm{BamHI}$ \\
\hline Primer 6 & $p f k$ & CTCTGAGCTCAGTCAAGCCTAGGTCACAGT & Sacl \\
\hline Primer 7 & $\mathrm{pCH}$ & GGATCCGATATCCTGCAGGAG & \\
\hline Primer 8 & $\mathrm{pCH}$ & CTCGACCAACAGTTGCGCAGC & \\
\hline Primer 9 & $\operatorname{araR}$ & CTCTCTGCAGGCGCTCAATGCTTGACAGCG & Pstl \\
\hline Primer 10 & $\operatorname{araR}$ & CTCTAAGCTTCCGACGGCATCTACACCGAT & HindIII \\
\hline Primer 11 & $\operatorname{araR}$ & CTCTGAATTCTCGTGGAGGTTTCGCAGGAA & EcoRI \\
\hline Primer 12 & $\operatorname{araR}$ & СTCTCTGCAGGCTGCCAATGACCAGATGGC & Pstl \\
\hline
\end{tabular}

a The restriction site overhangs used in the cloning procedure are underlined

\section{Assay methods}

Culture broth was centrifuged $\left(15,000 \times g, 4{ }^{\circ} \mathrm{C}, 10 \mathrm{~min}\right)$, and the concentrations of $\mathrm{D}$-glucose and L-arabinose in the supernatant were measured as follows. The concentration of L-arabinose and D-glucose was assayed enzymatically using an L-Arabinose/D-Galactose Assay kit (Megazyme, Wicklow, Ireland) and a Glucose CII test kit (Wako Pure Chemical Industries, Osaka, Japan), respectively, according to the manufacturer's instructions. Cell mass was estimated by measuring the $\mathrm{OD}_{600}$ using a spectrophotometer (U-3010; Hitachi, Tokyo, Japan).

Major metabolites of the central metabolic pathways [e.g., glycolysis, the PPP, and tricarboxylic acid (TCA) cycle] were analyzed using an ion-pairing LC-MS/MS method [42]. Dried cell extracts were dissolved in $50 \mu \mathrm{L}$ of MilliQ water for LC-MS/MS-based profiling and quantitation of 30 intracellular C. glutamicum metabolites. The following metabolites were analyzed: sugar phosphates [glucose-6-phosphate (G6P), fructose-6-phosphate (F6P), frucotose-1,6-bisphosphate (FBP), dihydroxyacetone phosphate (DHAP), glyceraldehyde-3-phosphate (GAP), 2- and 3-phosphoglycerate (2PG + 3PG), phosphoenolpyruvate (PEP) 6-phosphoglycerate (6PG), ribulose-5-phosphate (Rib5P), ribose-5-phosphate (R5P), $\mathrm{X} 5 \mathrm{P}$, erythrose-4-phosphate (E4P), and sedoheptulose7-phosphate (S7P)]; organic acids [aconitate, citrate (Cit), fumarate (Fum), isocitrate (IsoCit), malate (Mal), oxaloacetate (OXA), 2-oxoglutarate (AKG), pyruvate, and succinate (Suc)]; nucleotides [adenosine diphosphate (ADP) and ATP]; and coenzymes [acetyl-CoA (AcCoA), oxidized and reduced nicotinamide adenine dinucleotide $\left(\mathrm{NAD}^{+}\right.$and $\mathrm{NADH}$, respectively), and oxidized and reduced nicotinamide adenine dinucleotide phosphate $\left(\mathrm{NADP}^{+}\right.$and NADPH, respectively)]. Metabolites were quantified as described previously [43] using an Agilent
1200 series MS and Agilent 6460 with Jet Stream Technology LC-MS/MS system (Agilent Technologies, Waldbronn, Germany) equipped with a Maestro C18 column $(2.1 \times 150 \mathrm{~mm}, 3-\mu \mathrm{m}$ particle size; Shimadzu, Kyoto, Japan).

\section{Extraction of metabolic intermediates}

For quantitative metabolomics, C. glutamicum cells were subjected to cold methanol quenching [44] with a slight modification, as follows. A total of $15 \mathrm{~mL}$ of liquid culture at $\mathrm{OD}_{600}$ of 2.0 was withdrawn from medium and immediately sprayed into a $50-\mathrm{mL}$ centrifugal tube (LMS Co., Ltd., Tokyo, Japan) containing 2.0 volumes of $40 \%$ (v/v) aqueous methanol at $-25{ }^{\circ} \mathrm{C}$. After sampling, the content of each tube was immediately mixed by vortexing for $5 \mathrm{~s}$ to quench cellular metabolism and subsequently centrifuged $\left(4000 \times g, 5 \mathrm{~min},-9^{\circ} \mathrm{C}\right)$. After decanting of the supernatant, cell pellets were washed with $8 \mathrm{~mL}$ of $0.8 \%(\mathrm{w} / \mathrm{v}) \mathrm{NaCl}$ at $4{ }^{\circ} \mathrm{C}$ and subsequently centrifuged again $\left(4000 \times g, 5 \mathrm{~min},-9{ }^{\circ} \mathrm{C}\right)$. After decanting the supernatant again, the tubes containing the cell pellets were submerged directly into liquid nitrogen and subsequently stored at $-80{ }^{\circ} \mathrm{C}$ until metabolite extraction. For metabolite extraction, $3.0 \mathrm{~mL}$ of cold methanol $\left(-25^{\circ} \mathrm{C}\right)$ containing $(+)$-camphor-10-sulfonic acid $(18 \mu \mathrm{g} / \mathrm{L})$ was added to each tube as an internal standard for quantitative LC-MC/MS analysis. The tubes were vortexed for $30 \mathrm{~s}$, and the resulting cell suspensions were incubated at $-30{ }^{\circ} \mathrm{C}$ for $1 \mathrm{~h}$, after which, $1.5 \mathrm{~mL}$ of the suspensions were transferred to $15-\mathrm{mL}$ centrifuge tubes (LMS Co., Ltd.) containing $2.1 \mathrm{~mL}$ of chloroform and $1.5 \mathrm{~mL}$ of distilled water, which were then mixed by vortexing for $5 \mathrm{~s}$. After centrifugation of the resulting suspensions at $15,000 \times g$ at $4{ }^{\circ} \mathrm{C}$ for $5 \mathrm{~min}$, the upper phases were transferred to new tubes and then dried under vacuum. The 
dried samples were stored at $-80{ }^{\circ} \mathrm{C}$ until metabolite analysis.

\section{Statistics}

Differences in sugar and metabolic intermediate concentrations and differences in cell density between the fermentation media were compared using the paired Student's $t$ test. A $p$ value of $<0.05$ was considered statistically significant.

\section{Results}

\section{Simultaneous utilization of two sugars was suppressed} in the presence of excess glucose

Before mixed sugar utilization, sugar consumption and cell growth were investigated in mineral salt medium containing either $\mathrm{D}$-glucose or L-arabinose as sole carbon source $(15 \mathrm{~g} / \mathrm{L})$ in order to measure the rate of sugar consumption in the absence of a second carbon source. Wild-type strain ATCC 31831 was found to have an equivalent capacity for both L-arabinose metabolism and $D$-glucose metabolism in the absence of the second carbon source. L-Arabinose was consumed at a rate about equal to that of D-glucose $(0.180$ and $0.167 \mathrm{~g} / \mathrm{h} / \mathrm{g}$ dry cell weight (DCW), respectively), and the specific growth rate was higher on D-glucose than on L-arabinose [specific growth rate $(\mu)=0.40$ and $0.36 \mathrm{~h}^{-1}$, respectively] (Fig. 2a).

To examine the effect of concentration on the simultaneous utilization of two sugars, strain ATCC 31831 was aerobically grown in mineral salt medium containing $\mathrm{L}$-arabinose and D-glucose as the carbon sources at concentrations of 3.6 or $15 \mathrm{~g} / \mathrm{L}$ each. In the sugar mixture of L-arabinose and D-glucose at the low concentration (3.6 g/L each), both D-glucose and L-arabinose were consumed simultaneously at the same rate (Fig. 2b). In contrast, the high concentration sugar mixture ( $15 \mathrm{~g} / \mathrm{L}$ each), elicited hindered L-arabinose metabolism due to excess D-glucose. After $30 \mathrm{~h}$ of cultivation, glucose was preferentially and completely consumed, while L-arabinose was consumed at a relatively lower rate with complete consumption at $49 \mathrm{~h}$ (Fig. 2b). The specific growth rate of the wild-type strain grown on the sugar mixture was significantly higher at the high concentration of $15 \mathrm{~g} / \mathrm{L}$ each compared with the low concentration of $3.6 \mathrm{~g} / \mathrm{L}$ each ( $\mu=0.35$ and $0.31 \mathrm{~h}^{-1}$, respectively; $\left.p<0.001\right)$.

Using only a single carbon source, the specific consumption rate of $\mathrm{L}$-arabinose and $\mathrm{D}$-glucose were comparable (Additional file 1: Table S1). In contrast, L-arabinose metabolism was apparently lower than D-glucose metabolism using the two carbon sources (Fig. 2b). At $23 \mathrm{~h}$ of cultivation, the specific consumption rates of $\mathrm{L}$-arabinose and D-glucose using the two carbon sources were 0.043 and $0.070 \mathrm{~g} / \mathrm{h} / \mathrm{g}$ DCW, respectively (Fig. 2 and Additional file 1: Table S1). These results suggest that the limited carbon supply at low concentrations of D-glucose and $\mathrm{L}$-arabinose (3.6 g/L each) restricts the growth of C. glutamicum and that excess glucose leads to preferential utilization of D-glucose over L-arabinose $(15 \mathrm{~g} / \mathrm{L})$.
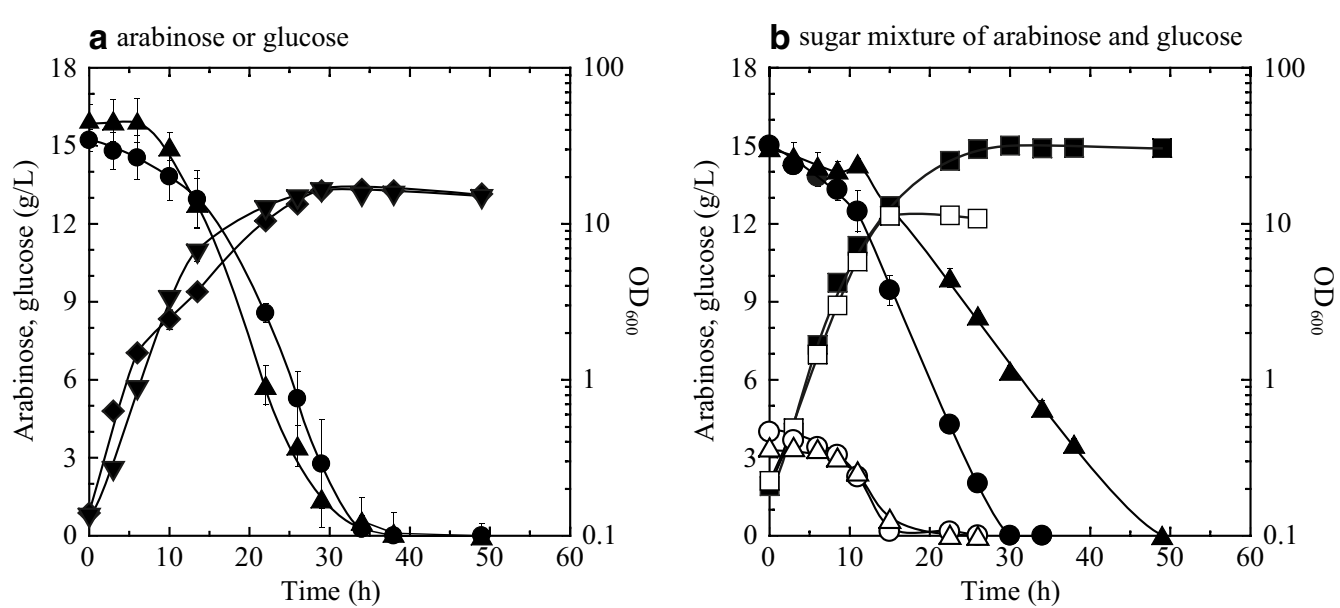

Fig. 2 Consumption of L-arabinose and/or D-glucose by wild-type strain ATCC 31831 in mineral salt medium containing L-arabinose and D-glucose individually (a) or collectively (b). The wild-type strain was grown aerobically to late log phase in A medium (containing $20 \mathrm{~g} / \mathrm{L}$ of $\mathrm{L}$-arabinose and $20 \mathrm{~g} / \mathrm{L}$ of D-glucose) and then inoculated to an initial $\mathrm{OD}_{600}$ of 0.2 into mineral salt BT medium. Using only a single carbon source (a), either L-arabinose or D-glucose was added to BT medium ( $15 \mathrm{~g} / \mathrm{L}$; solid symbols). Using two carbon sources (b), a mixture of L-arabinose and D-glucose was added to BT medium to final concentrations of either $3.6 \mathrm{~g} / \mathrm{L}$ (open symbols) or $15 \mathrm{~g} / \mathrm{L}$ (solid symbols). Cells were growth on either L-arabinose (reverse triangles) or D-glucose (diamonds) as single carbon sources, and also as a sugar mixture (squares). The concentrations of L-arabinose (empty triangles) and D-glucose (empty circles) are indicated. Data are plotted as the average \pm standard deviation calculated from the results of triplicate individual experiments 


\section{Metabolome analysis of cells grown on glucose or arabinose}

To identify the metabolic bottlenecks in the metabolism of L-arabinose, the metabolic profiles of wild-type C. glutamicum cells grown aerobically on either D-glucose or L-arabinose as the sole carbon and energy source were compared. Cells growing aerobically were harvested at exponential phase $\left(\mathrm{OD}_{600}=1.5\right)$ and quenched immediately with liquid nitrogen for the extraction of metabolic intermediates. Consequently, the enzymatic activities of phosphofructokinase and pyruvate dehydrogenase, which convert F6P to FBP and pyruvate to AcCoA, respectively, were found to be major bottlenecks in D-glucose metabolism. As compared with cells grown on L-arabinose, the concentrations of G6P and F6P were significantly higher in cells grown on D-glucose, whereas the concentration of FBP was significantly lower (Fig. 3). In addition, the concentration of pyruvate was significantly higher in cells grown on D-glucose as compared with cells grown on L-arabinose, whereas the concentration of AcCoA was significantly lower. In contrast, the enzymatic activities of pyruvate kinase and citrate synthase, which convert PEP to pyruvate and AcCoA and OXA to Cit, respectively, were found to be major bottlenecks in L-arabinose metabolism. As compared with cells grown on D-glucose, the concentration of PEP was significantly higher in cells grown on L-arabinose, whereas the concentration of pyruvate was significantly lower. In addition, the concentrations of AcCoA and OXA were significantly higher and that of Cit significantly lower in cells grown on L-arabinose compared with cells grown on D-glucose. Furthermore, flux through the non-oxidative PPP was found to be higher during L-arabinose metabolism than during D-glucose metabolism. The concentrations of the PPP intermediates R5P, Rib5P, S7P, and X5P were significantly higher in cells grown on L-arabinose compared with cells grown on D-glucose.

\section{Metabolic engineering for simultaneous utilization of D-glucose and L-arabinose}

To identify the critical bottlenecks in the simultaneous utilization of L-arabinose and D-glucose, three potential rate-limiting enzymes were selected for analysis based on metabolomic data (Fig. 3): citrate synthase, phosphofructokinase, and pyruvate kinase. Each of these enzymes was individually overexpressed in the wild-type strain. Pyruvate kinase or citrate synthase was overexpressed to eliminate major bottleneck in L-arabinose metabolism, whereas phosphofructokinase was overexpressed to eliminate the major bottleneck in D-glucose metabolism.

Overexpression of citrate synthase reduced the consumption of both D-glucose and L-arabinose, and the specific growth rate of the recombinant strain declined by $40 \%$ compared with the wild-type strain $(\mu=0.21$ and $0.35 \mathrm{~h}^{-1}$, respectively) (Figs. $4 \mathrm{a}$ and $2 \mathrm{~b}$ ). Conversely, overexpression of pyruvate kinase (NCgl2008) reduced the time required for the complete consumption of L-arabinose without any effect on the time for D-glucose consumption, as compared to the wild-type strain (Figs. 4b and 2b). At $23 \mathrm{~h}$ of cultivation, the specific consumption rates of $\mathrm{L}$-arabinose and $\mathrm{D}$-glucose were 0.050 and $0.102 \mathrm{~g} / \mathrm{h} / \mathrm{g} \mathrm{DCW}$, respectively. The rate for L-arabinose consumption was $16 \%$ higher than that of the wild-type strain (Additional file 1: Table S1). In addition, the specific growth rate of the recombinant strain $31831 / \mathrm{pCH} p y k\left(\mu=0.28 \mathrm{~h}^{-1}\right)$ was lower than that of the wild type strain. Overexpression of the endogenous pyruvate kinase isozyme (NCgl2809) did not effectively improve mixed sugar consumption (data not shown).

By contrast, overexpression of phosphofructokinase promoted preferential utilization of D-glucose over L-arabinose. As compared with the wild-type strain, strain 31831/pCHpfk increased D-glucose consumption but markedly reduced L-arabinose consumption, although the specific growth rate of the recombinant strain increase by $6 \%\left(\mu=0.33 \mathrm{~h}^{-1}\right)$ (Figs. $4 \mathrm{c}$ and $2 \mathrm{~b}$ ). The recombinant strain $31831 / \mathrm{pCH}$ pyk exhibited 2.2fold higher pyruvate kinase activity and a significantly decrease in the concentration gap between D-glucose and L-arabinose after $23 \mathrm{~h}$ of cultivation as compared with the wild-type strain (Table 3 ). Therefore, pyruvate kinase (NCgl2008) activity is likely a major bottleneck in the simultaneous utilization of $\mathrm{L}$-arabinose and D-glucose.

\footnotetext{
(See figure on next page.)

Fig. 3 Metabolic profile of aerobically growing wild-type strain C. glutamicum ATCC 31831. Relative abundance of metabolic intermediates in C. glutamicum cells during aerobic growth in BT medium containing either D-glucose (open columns) or L-arabinose (gray columns) as the sole carbon source are shown. For the profiling experiment, the wild-type strain was grown aerobically to late log phase in A medium containing $D$-glucose $(20 \mathrm{~g} / \mathrm{L})$ and $\mathrm{L}$-arabinose $(20 \mathrm{~g} / \mathrm{L})$, and the culture was then inoculated to an initial $\mathrm{OD}_{600}$ of 0.2 into BT medium containing either D-glucose (20 $\left.\mathrm{g} / \mathrm{L}\right)$ or $\mathrm{L}$-arabinose $(20 \mathrm{~g} / \mathrm{L})$ as the sole carbon source. The cells were harvested at mid log phase $\left(\mathrm{OD}_{600}=1.5\right)$ and subjected to metabolic profiling. Data are presented as average \pm standard deviation calculated from the results of triplicate individual experiments. Single and double asterisks indicate $p$ values of $<0.05$ and $<0.01$, respectively
} 


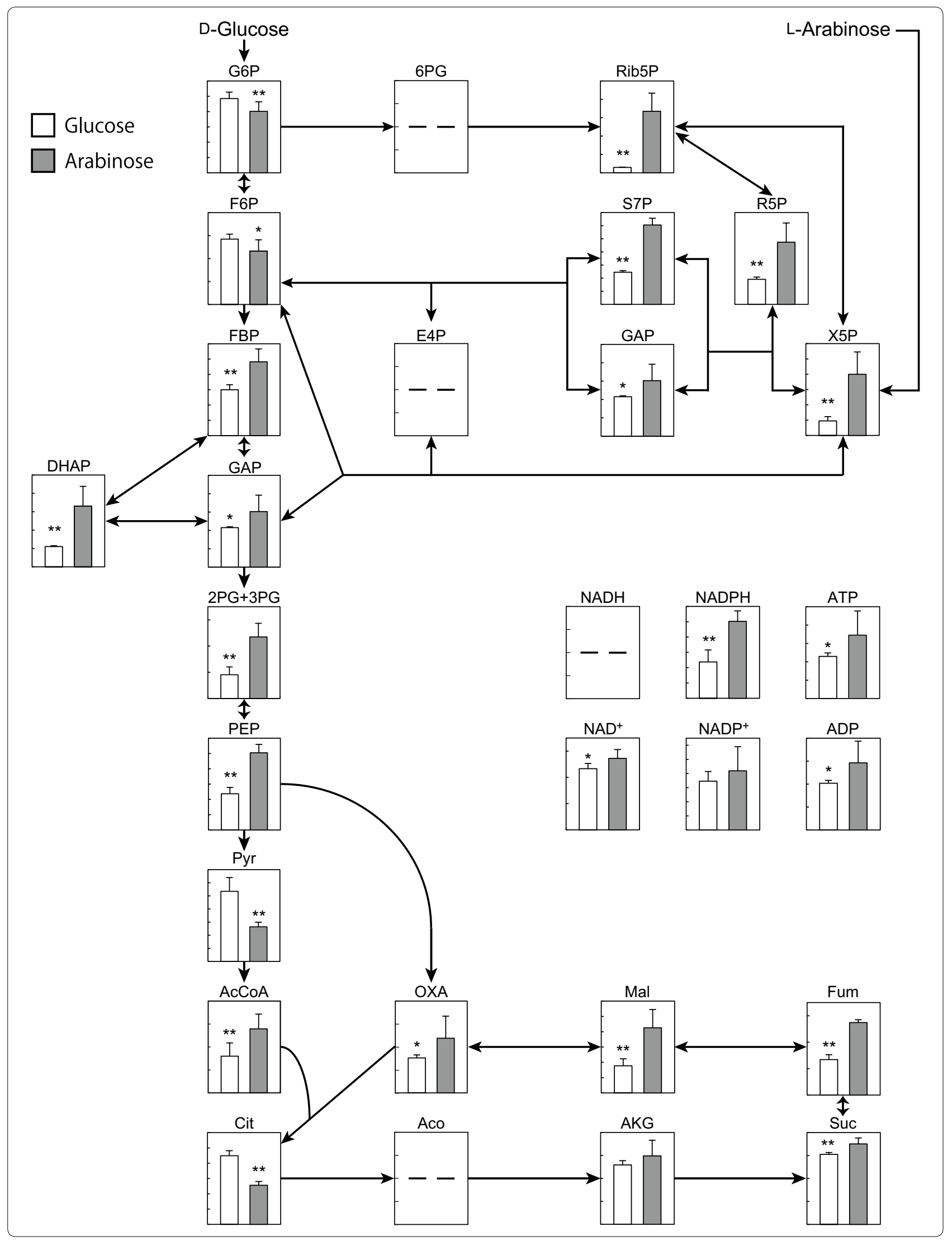



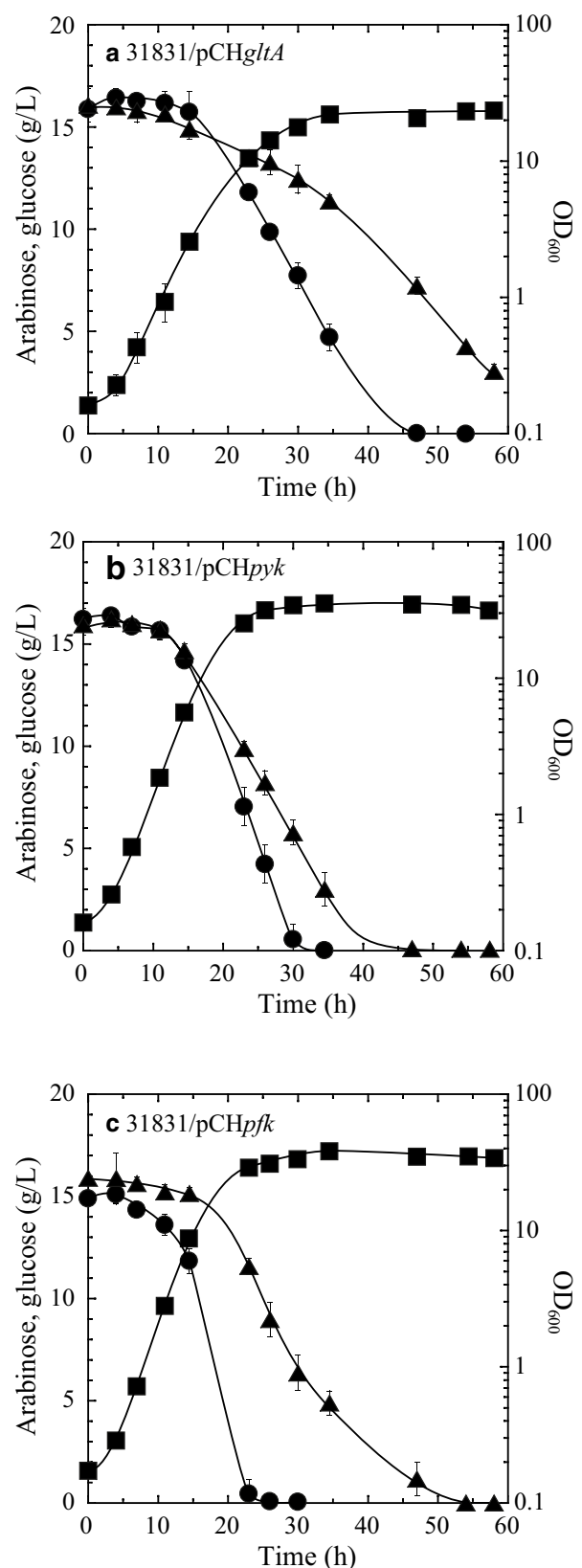

Fig. 4 Utilization of a mixture of L-arabinose and D-glucose by aerobically growing cells of recombinant strains expressing citrate synthase (a), pyruvate kinase (b), or phosphofructokinase (c) genes. Recombinant strains were grown aerobically to late log phase in A medium (containing $20 \mathrm{~g} / \mathrm{L}$ of L-arabinose and $20 \mathrm{~g} / \mathrm{L}$ of D-glucose) and then inoculated to an initial $\mathrm{OD}_{600}$ of 0.2 into mineral salt BT medium containing L-arabinose and D-glucose ( $15 \mathrm{~g} / \mathrm{L}$ each) as the carbon sources. Cell growth (squares) and the concentrations of L-arabinose (triangles) and D-glucose (circles) are indicated. Data are average \pm standard deviation calculated from the results of triplicate individual experiments
Effect of araR deletion in combination with increased pyruvate kinase

Deletion of $\operatorname{araR}$ gene, which encodes a repressor of the L-arabinose-catabolizing genes $\operatorname{ara} A, \operatorname{araB}$, and $\operatorname{araD}$ and the L-arabinose transporter gene $\operatorname{araE}$ (Fig. 1), leads to constitutive expression of these four genes [21]. To match the consumption rates of $\mathrm{D}$-glucose and $\mathrm{L}$-arabinose more closely, pyruvate kinase was overexpressed in the araRdeletion mutant $(\triangle a r a R)$. With overexpression of pyruvate kinase, the recombinant strain $\triangle a r a R / \mathrm{pCH} p y k$ consumed $\mathrm{L}$-arabinose and $\mathrm{D}$-glucose at a comparable rate until $30 \mathrm{~h}$ of cultivation, whereas the $\triangle a r a R$ mutant utilized D-glucose preferentially after $17 \mathrm{~h}$ of cultivation (Fig. 5). Compared with the $\triangle a r a R$ mutant, strain $\triangle a r a R / \mathrm{pCH} p y k$ exhibited significantly lower specific growth rates $(\mu=0.29$ and $0.21 \mathrm{~h}^{-1}$, respectively) and reduced D-glucose consumption rates. Compared with the $\Delta a r a R$ mutant at $23 \mathrm{~h}$ of cultivation, strain $\triangle a r a R / \mathrm{pCH} p y k$ reduced the specific consumption rate of D-glucose $(0.101$ and $0.081 \mathrm{~g} / \mathrm{h} / \mathrm{g}$ $\mathrm{DCW}$, respectively) and increased the specific consumption rate of L-arabinose $(0.053$ and $0.078 \mathrm{~g} / \mathrm{h} / \mathrm{g} \mathrm{DCW}$, respectively) (Additional file 1: Table S1). Meanwhile, total consumption rate of $\mathrm{L}$-arabinose and $\mathrm{D}$-glucose was comparable between both strains (approximately $0.16 \mathrm{~g} / \mathrm{h} / \mathrm{g}$ $\mathrm{DCW})$. Consequently, the concentration gap between $\mathrm{D}$-glucose and L-arabinose was reduced in culture with strain $\triangle a r a R / \mathrm{pCH} p y k$, which exhibited 3.6-fold higher pyruvate kinase activity as compared to strain $\triangle a r a R$ (Table 3). Thus, increased pyruvate kinase activity in combination with increased L-arabinose catabolism matched the consumption rates of $\mathrm{L}$-arabinose and $\mathrm{D}$-glucose in the high-concentration mixture of both carbon sources.

\section{Metabolic profiling of cells simultaneously utilizing D-glucose and L-arabinose}

To investigate differences in the metabolism of cells exhibiting preferential or simultaneous utilization of D-glucose in the presence of L-arabinose, transient states of metabolic profiles during consumption of mixtures of $\mathrm{D}$-glucose and $\mathrm{L}$-arabinose were probed by metabolome analysis. The wild-type strain was used as a control to demonstrate preferential utilization of D-glucose over L-arabinose, whereas the recombinant strain $\triangle a r a R / \mathrm{pCH} p y k$ was used to examine simultaneous utilization. In addition, strain $31831 / \mathrm{pCH} p y k$ was used to investigate the effect of increased pyruvate kinase activity alone on the metabolic profile. Overall, increased pyruvate kinase activity had a marked impact on the metabolic profile, whereas synergetic effects involving araR 
Table 3 Utilization of D-glucose and L-arabinose and pyruvate kinase activity of aerobically grown wild-type strain, araRdeletion mutant, and recombinant strains expressing pyruvate kinase

\begin{tabular}{|c|c|c|c|c|}
\hline \multirow[t]{2}{*}{ Strain $^{a}$} & \multicolumn{2}{|c|}{ Sugar concentration $(g / L)^{b}$} & \multirow[t]{2}{*}{$\Delta$ Arabinose-glucose $(\mathrm{g} / \mathrm{L})^{c}$} & \multirow{2}{*}{$\begin{array}{l}\text { Pyruvate kinase activity } \\
\text { ( } \mu \mathrm{mol} / \mathrm{min} / \mathrm{mg} \text { protein })^{\mathrm{d}}\end{array}$} \\
\hline & D-Glucose & L-Arabinose & & \\
\hline Wild type & $3.5 \pm 1.5$ & $9.2 \pm 0.4$ & $5.7 \pm 1.2$ & $0.54 \pm 0.02$ \\
\hline$\triangle a r a R$ & $2.1 \pm 1.5$ & $8.4 \pm 0.3$ & $6.2 \pm 1.2$ & $0.45 \pm 0.06$ \\
\hline pCHpyk & $7.8 \pm 0.8$ & $9.5 \pm 0.8$ & $1.7 \pm 1.2$ & $1.17 \pm 0.04$ \\
\hline$\triangle a r a R / p C H p y k$ & $6.5 \pm 1.3$ & $7.1 \pm 0.5$ & $0.6 \pm 0.8$ & $1.61 \pm 0.10$ \\
\hline
\end{tabular}

a Recombinant strains were grown aerobically to late log phase in A medium containing $20 \mathrm{~g} / \mathrm{L}$ of $\mathrm{L}$-arabinose and $20 \mathrm{~g} / \mathrm{L}$ of $\mathrm{D}$-glucose and then inoculated to an initial $\mathrm{OD}_{600}$ of 0.2 into mineral salt BT medium containing L-arabinose and D-glucose $(15 \mathrm{~g} / \mathrm{L}$ each) as carbon sources

b After $23 \mathrm{~h}$ of cultivation, the culture supernatant was collected by centrifugation and subjected to sugar analysis. Data shown are average \pm standard deviation calculated from the results of triplicate individual experiments

c Values were determined based on the concentration of D-glucose and L-arabinose after $23 \mathrm{~h}$ of cultivation. Data are average \pm standard deviation calculated from the results of triplicate individual experiments

d Pyruvate kinase activity was determined using crude cell extract prepared from cells grown for $23 \mathrm{~h}$ in mineral salt BT medium containing L-arabinose and D-glucose (15 g/L each) as carbon sources. Data are average \pm standard deviation calculated from the results of triplicate analyses

\section{a $\triangle \operatorname{araR}$}

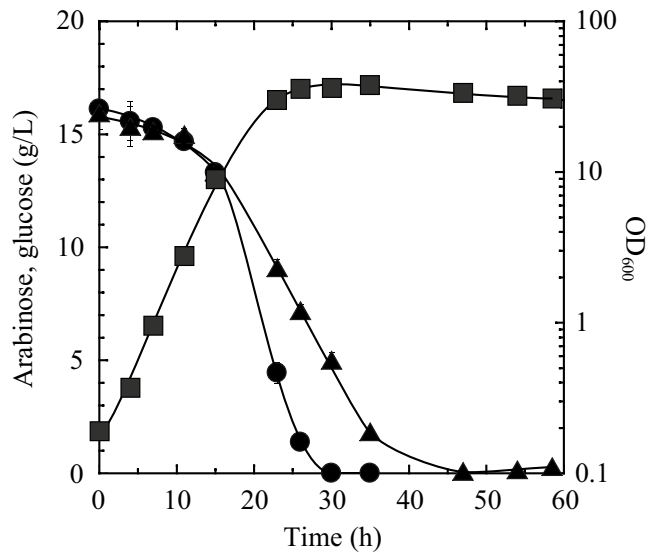

\section{b $\triangle \operatorname{araR} / \mathrm{pCH} p y k$}

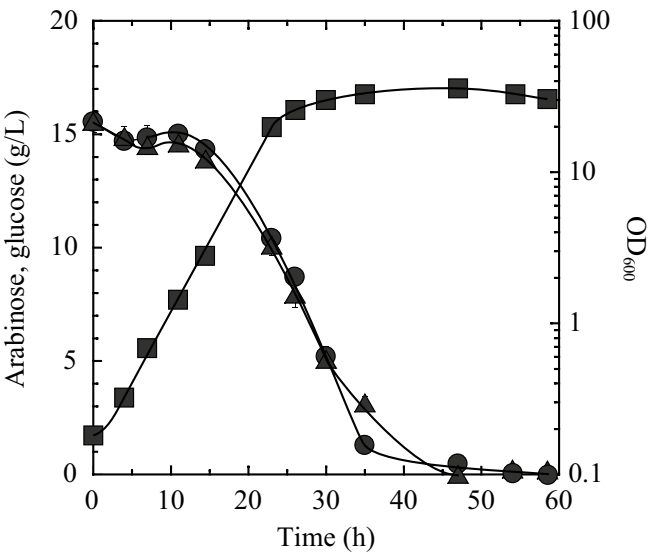

Fig. 5 Utilization of a mixture of L-arabinose and D-glucose by the aerobically growing araR-deletion mutant (a) and its recombinant strain expressing pyruvate kinase (b). Both strains were grown aerobically to late log phase in A medium (containing $20 \mathrm{~g} / \mathrm{L}$ of $\mathrm{L}-\mathrm{arabinose}$ and $20 \mathrm{~g} / \mathrm{L}$ of D-glucose) and then inoculated to an initial $\mathrm{OD}_{600}$ of 0.2 into mineral salt BT medium containing L-arabinose and $\mathrm{D}$-glucose (15 g/L respectively) as the carbon sources. Cell growth (squares) and concentrations of L-arabinose (triangles) and D-glucose (circles) are indicated. Data are average \pm standard deviation calculated from the results of triplicate individual experiments

deletion on the metabolic profile were relatively limited (Fig. 6).

In the oxidative PPP, levels of 6PG were significantly reduced by the overexpression of pyruvate kinase (Fig. 6).
In the reductive PPP, by contrast, strain $\Delta a r a R / p C H p y k$ consuming $\mathrm{D}$-glucose and L-arabinose simultaneously exhibited the highest levels of the L-arabinose catabolites Rib5P and X5P at $11 \mathrm{~h}$ of cultivation and retained high

(See figure on next page.)

Fig. 6 Time course metabolomics of aerobically growing wild-type C. glutamicum ATCC 31831 (black diamonds) and recombinant strains overexpressing pyruvate kinase in the absence or presence of araR deletion (31831/pCHpyk, blue triangles; $\triangle a r a R / p C H p y k$, red circles). Relative abundances of metabolic intermediates in cells during aerobic growth in BT medium containing a mixture of D-glucose and L-arabinose are shown. The $X$-axis indicates cultivation time (h). For the profiling experiment, three strains were grown aerobically to late log phase in A medium containing $20 \mathrm{~g} / \mathrm{L}$ of $\mathrm{L}$-arabinose and $20 \mathrm{~g} / \mathrm{L}$ of D-glucose, and the culture was then inoculated to an initial $\mathrm{OD}_{600}$ of 0.2 into BT medium containing a mixture of D-glucose and L-arabinose as the carbon sources (15 g/L each). The cells were harvested at 11, 17, and $23 \mathrm{~h}$ of cultivation and subsequently subjected to metabolome analysis. Data are presented as average \pm standard deviation calculated from the results of triplicate individual experiments. The concentration of erythrose-4-phosphate was below the detection limit 


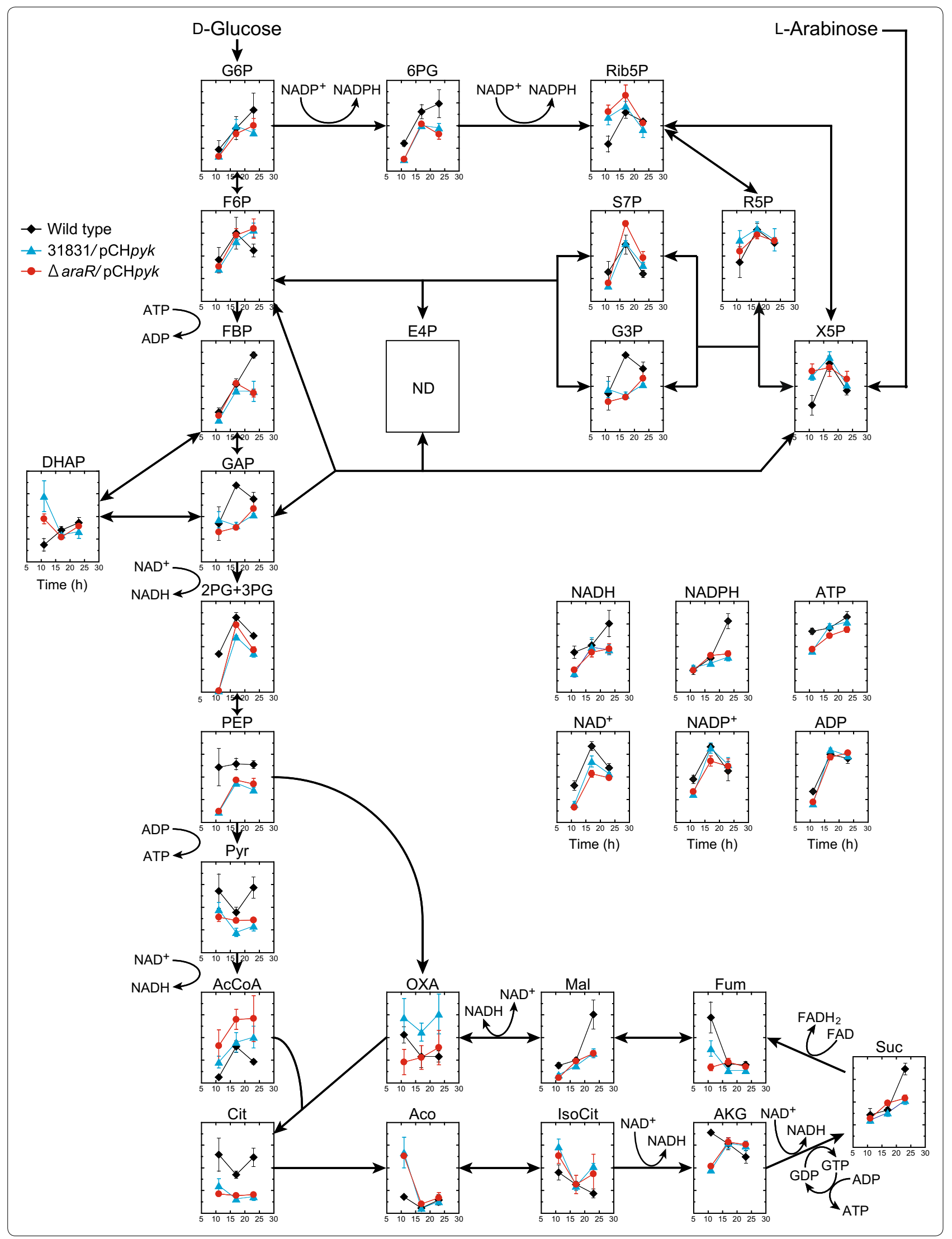


$\mathrm{X} 5 \mathrm{P}$ levels throughout the observed period of $11-23 \mathrm{~h}$, as compared with the wild-type strain. After $17 \mathrm{~h}$ of cultivation, S7P levels were significantly increased only in strain $\triangle a r a R / p C H p y k$. No significant difference in expression of $t k t$ (encoding transketolase) was observed between the wild-type and $\triangle a r a R / \mathrm{pCH} p y k$ strains at $11 \mathrm{~h}$ of cultivation, whereas the expression of tal (encoding transaldolase) at 11 and $23 \mathrm{~h}$ was markedly higher in $\Delta a r a R /$ $\mathrm{pCH}$ yk than in the wild-type strain (Additional file 1: Table S2).

L-Arabinose catabolites through the reductive PPP enter into glycolysis via F6P and GAP. No significant difference was observed in the level of the hexose phosphate F6P at 11 and $17 \mathrm{~h}$ of cultivation, while the level of the triose phosphate GAP was reduced by the overexpression of pyruvate kinase at 17 and $23 \mathrm{~h}$ of cultivation (Fig. 6). Levels of the glycolytic intermediates PEP and pyruvate were markedly affected by pyruvate kinase activity. Throughout the observed period of 11-23 h, overexpression of pyruvate kinase reduced PEP and pyruvate levels significantly, as compared with the wild-type strain. Conversely, AcCoA levels increased following overexpression of pyruvate kinase and increased further in combination with increased L-arabinose catabolism ( $\triangle a r a R / \mathrm{pCH} p y k)$. No significant differences were observed in the expression levels of genes encoding key enzymes in D-glucose uptake and glycolysis, except for reduced levels of $p t s I$ in strain $\Delta a r a R / \mathrm{pCH} p y k$ at $11 \mathrm{~h}$ of cultivation (Additional file 1: Table S2). Thus, strain $\triangle a r a R / p C H p y k$ appeared to enhance the metabolic flux of triose phosphates, leading to elevated AcCoA levels during simultaneous sugar utilization.

Overexpression of pyruvate kinase also affected the profiles of the TCA cycle intermediates. Levels of Cit were significantly reduced by the overexpression of pyruvate kinase. Conversely, levels of the Cit precursors AcCoA and OXA varied depending on strain (Fig. 6), although the concentrations of OXA were relatively low (Additional file 1: Figs S1 and S2). Simultaneous utilization of L-arabinose and D-glucose appeared to attenuate reductive reactions dependent on $\mathrm{NAD}^{+}$and FAD as cofactors. At $11 \mathrm{~h}$ of cultivation, the two recombinant strains showed significantly increased aconitate levels and significantly reduced AKG levels, as compared with the wild-type strain. In addition, both recombinant strains showed significantly lower fumarate levels but comparable succinate levels, as compared with the wildtype strain.

Simultaneous utilization of L-arabinose and D-glucose affected energy state and redox balance in the cell. Strain $\triangle a r a R / \mathrm{pCH} p y k$ has lower-energy and more-oxidative (low ATP/ADP and NADPH/NADP ${ }^{+}$ratios) states during simultaneous utilization of $\mathrm{D}$-glucose and $\mathrm{L}$-arabinose
(23 h), compared with the wild-type strain preferentially utilizing D-glucose. At $23 \mathrm{~h}$ of cultivation, the ATP/ADP, $\mathrm{NADH} / \mathrm{NAD}^{+}$, and NADPH/NADP ${ }^{+}$ratios in the wildtype strain were $0.757,0.0016$, and 1.287 , respectively, whereas those in the strain $\triangle a r a R / \mathrm{pCH} p y k$ were 0.579 , 0.0013 , and 0.633 , respectively. Throughout the observed period of $17-23 \mathrm{~h}$ of simultaneous sugar utilization, ATP levels were lower in strain $\Delta a r a R / \mathrm{pCH} p y k$ relative to strain 31831/pCHpyk.

\section{Discussion}

Metabolome analysis has become a powerful tool for comprehensively investigating metabolic profiles [45]. In this study, metabolome analysis was used to identify potential bottlenecks in C. glutamicum metabolism of D-glucose and L-arabinose (Fig. 3) via overexpression of predicted rate-limiting enzymes (Fig. 4). Combining metabolome analysis and metabolic engineering enabled the development of an engineered metabolic pathway in which D-glucose and L-arabinose can be utilized simultaneously in the presence of excess D-glucose (Fig. 5). In a previous study, stepwise overexpression of four genes encoding glycolytic enzymes improved glucose metabolism [46]. In the present study, the results of metabolome analysis revealed that manipulation of only two genes is necessary for simultaneous utilization of D-glucose and $\mathrm{L}$-arabinose at the same rate. Several laboratories have investigated the metabolic status of C. glutamicum with the ultimate goal of improving D-glucose consumption and fermentation $[35,47,48]$ however optimization of $\mathrm{L}$-arabinose consumption has not yet been reported. The present study of C. glutamicum is the first to demonstrate that metabolome analysis can provide insight into bottlenecks that can be overcome by the rational design metabolic pathways, leading to optimization of simultaneous consumption rates of D-glucose and L-arabinose.

Previous strategies to avoid CCR have depended on inactivation of the PTS, resulting in markedly reduced rates of D-glucose utilization in both E. coli and C. glutamicum $[49,50]$. In contrast to the previous approach, the present strategy preserved the indigenous PTS with a high efficiency for D-glucose uptake, and the resulting metabolically engineered strains utilized D-glucose without any decline in consumption rate (Fig. 5). The engineered strain $\Delta a r a R / \mathrm{pCH} p y k$ utilized D-glucose and L-arabinose simultaneously at exact the same rate (Fig. 5). Previous PTS ${ }^{-}$mutants of both E. coli and $C$. glutamicum demonstrated reduced or incomplete sugar utilization in the presence of multiple sugars $[13,50]$. Therefore, the present PTS-conserved strategy is an novel metabolic engineering approach that avoids CCR without any decline in sugar utilization rate and does not require adaptive laboratory evolution selection that could 
result in unexpected mutations in the genome and hinder further metabolic engineering to develop a microbial platform [51].

Pyruvate kinase activity was a major bottleneck in $\mathrm{L}$-arabinose metabolism, and overexpression of the enzyme was found to be a prerequisite for simultaneous utilization of D-glucose and L-arabinose (Fig. 5 and Additional file 1: Table S1). The increased pyruvate kinase activity increased the specific consumption rate of L-arabinose yet only moderately reduced the specific consumption rate of $\mathrm{D}$-glucose, particularly in combination with araR deletion (Figs. 4 and 5 and Additional file 1: Table S1). PEP, the substrate of pyruvate kinase, represents the switch point in the carbon flux distribution in bacteria [52]. For pentose metabolism, the flux through PEP to pyruvate in glycolysis depends completely on pyruvate kinase activity [53]. For D-glucose metabolism, by contrast, pyruvate kinase serves as a bypass in the flux, as $50 \%$ of the PEP in the glycolysis is converted into pyruvate by the PTS [14]. Thus, increased pyruvate kinase activity has two physiologic implications for multiple sugar consumption: promotion of pentose flux into glycolysis and slight depression of D-glucose uptake mediated by PTS owing to reduce available PEP for the PTS (Fig. 1).

As the specific consumption rate of L-arabinose increased, both specific growth rates and intracellular ATP levels were reduced (Fig. 6 and Additional file 1: Table S1). Pyruvate kinase-dependent pentose metabolism consumes more ATP than D-glucose metabolism mediated by PTS [54]. Thus, the more L-arabinose consumption leads to the less ATP generation. In the present study, ATP levels were lower in strain $\triangle a r a R / p C H p y k$ than the wild-type strain (Fig. 6). Consequently, reduced ATP levels led to reduced specific growth rate of recombinant strains overexpressing pyruvate kinase, particular in strain $\triangle a r a R / p C H p y k$ (Additional file 1: Table S1). Total sugar consumption rate of the recombinant strain $\triangle a r a R / \mathrm{pCH} p y k$ was not over that of the wild-type strain using only a single carbon source of either D-glucose or $\mathrm{L}$-arabinose, despite the specific consumption rate of $\mathrm{L}$-arabinose was 1.8 -fold higher in strain $\triangle a r a R / \mathrm{pCH} y y k$ than the wild-type strain (Additional file 1: Table S1). Expression levels of key genes for $\mathrm{L}$-arabinose and D-glucose were comparable or higher in strain $\triangle a r a R / \mathrm{pCH} p y k$ than the wild-type strain, except of $p t s I$ encoding enzyme I for PTS (Additional file 1: Table S2 and Fig. 1). These result support the hypothesis that the consumption of hexose and pentose mixtures is regulated metabolically rather than transcriptionally by intracellular conditions, such as energy state, redox balance, concentrations of metabolic intermediates or the capacity of glycolysis, as reported previously $[47,55-59]$.
Deletion of araR in combination with overexpression of pyruvate kinase was crucial to continue simultaneous utilization of D-glucose and L-arabinose after $17 \mathrm{~h}$ of cultivation (Fig. 5). Furthermore, the metabolome analysis revealed synergetic effects of the combined approach on metabolic profiles with elevated levels of L-arabinose catabolites (X5P, Rib5P, and S7P) and AcCoA in strain $\triangle \operatorname{araR} / \mathrm{pCH} y{ }^{2}$ (Fig. 6). The araR-deletion mutant expressed L-arabinose-catabolizing genes constitutively [21], and increased expression of these genes ( $\operatorname{ara} A, \operatorname{araB}$, and $\operatorname{araE}$ ) was observed in strain $\triangle a r a R$ when utilizing D-glucose and L-arabinose (Additional file 1: Table S2). The transporter AraE also uptakes D-xylose with a high efficiency [27]. Thus, the engineered pathway of strain $\triangle a r a R / p C H p y k$ can be also applied to co-utilization of D-glucose and D-xylose, which comprise a major fraction of lignocellulosic feedstocks [2]. In the PPP, expression levels of $t a l$ after 11 and $23 \mathrm{~h}$ were markedly higher in strain $\triangle a r a R / p C H p y k$ than the wild-type strain (Additional file 1: Table S2). Increased tal expression was also observed during D-xylose metabolism in E. coli [53]. It is therefore hypothesized that increased entry of L-arabinose catabolites enhances flux through the non-oxidative PPP in strain $\triangle a r a R / \mathrm{pCH} p y k$, resulting in matching of the rates of simultaneous utilization of $\mathrm{D}$-glucose and $\mathrm{L}$-arabinose.

With overexpression of pyruvate kinase, intracellular AcCoA levels were significantly elevated, while Cit levels were significantly reduced (Fig. 6). The increment of $\mathrm{AcCoA}$ in the strain overexpressing pyruvate kinase was markedly higher in combination with araR disruption, indicating that $\mathrm{L}$-arabinose catabolism and subsequent metabolism of triosephosphates was enhanced in strain $\Delta a r a R / p C H p y k$. Citrate synthase activity controls carbon allocation between anabolism and catabolism in $C$. glutamicum for L-lysine production [60] and also limits growth of E. coli on another pentose, D-xylose [61]. In addition, the present metabolome analysis revealed that citrate synthase activity is a major bottleneck in L-arabinose metabolism (Fig. 3). Our results indicate that citrate synthase activity becomes the new bottleneck in the engineered pathway for the simultaneous utilization of D-glucose and L-arabinose.

\section{Conclusions}

Based on the results of metabolome analysis, a metabolic pathway was designed and engineered to enable matching of the rates of simultaneous utilization of $\mathrm{D}$-glucose and L-arabinose by C. glutamicum. The metabolome analysis revealed potential bottlenecks to be eliminated for co-metabolism of D-glucose and $\mathrm{L}$-arabinose and provided the basis for the rational design of an engineered metabolic pathway. The 
manipulation of only two genes in combination with overexpression of pyruvate kinase and the deletion of araR enabled simultaneous and complete utilization of D-glucose and L-arabinose. The designed pathway for robust simultaneous sugar utilization is quite simple and unique, as inactivation of the PTS to avoid CCR and subsequent adaptive mutation to recover the D-glucose utilization rate are unnecessary. Such a simple strategy has not been reported, even in E. coli. Thus, the rational design strategy developed in the present study can be applied to develop a microbial platform for microbial production, as adaptive mutation that could produce unexpected DNA damage in the host genome is no longer necessary.

\section{Additional file}

Additional file 1: Table S1. Specific growth rates and specific sugar consumption rates by recombinant strains and the wild-type strain of $C$. glutamicum ATCC 31831. Table S2. Relative expression levels of genes in the ara cluster and central metabolic pathway in aerobically grown wild-type and araR-deletion mutants with/without pyk overexpression ( $\triangle$ araR and $\triangle a r a R / p C H p y k$ ). Fig. S1. Retention time comparison of liquid chromatography-mass spectrometry/mass spectrometry total ion current chromatograms of oxaloacetate (OXA) in C. glutamicum cells grown aerobically in BT medium containing sugar mixture of $\mathrm{D}$-glucose and L-arabinose ( $15 \mathrm{~g} / \mathrm{L}$ each). The authentic standards of OXA at the concentration of 2,10 , and $20 \mu \mathrm{M}(a, b, c)$ as well as their identified counterparts in $C$. glutamicum cells of the wild-type (d), and recombinant strains of 31831/ pCHpyk (e) and $\triangle a r a R / p C H p y k$ (f). OXA was identified based on retention time in chromatography and its mass spectrum. Concentration of OXA was determined with peak area of its multiple reaction monitoring (MRM) transition (131.0>87.1) in LC-MS/MS. Fig. S2. Mass spectra of identified oxaloacetate (OXA) in C. glutamicum cells grown aerobically in BT medium containing sugar mixture of D-glucose and $\mathrm{L}$-arabinose ( $15 \mathrm{~g} / \mathrm{L}$ each). The authentic standards of OXA at the concentration of 2, 10, and $20 \mu \mathrm{M}(\mathrm{A})$ as well as their identified counterparts in C. glutamicum cells of the wild-type (d), and recombinant strains of 31831/pCHpyk (e) and $\triangle \operatorname{araR/pCHpyk~(f).~}$ OXA was identified based on retention time in chromatography and its mass spectrum acquired by the targeted multiple reaction monitoring (MRM) transition (131.0>87.1). Table S3. Oligonucleotides used for qPCR in this study.

\section{Abbreviations}

AcCoA: acetyl CoA; ADP: adenosine 5'-diphosphate; AKG: 2-oxoglutarate; ATP: adenosine 5'-triphosphate; CCR: carbon catabolite repression; Cit: citrate; E4P: erythrose-4-phosphate; FBP: fructose-1,6-bisphosphate; F6P: fructose6-phosphate; GAP: glycelaldehyde-3-phosphate; G6P: glucose-6-phosphate; IsoCit: isocitrate; $\mathrm{NAD}^{+}$: nicotinamide adenine dinucleotide oxidized; $\mathrm{NADH}$ : nicotinamide adenine dinucleotide reduced; $\mathrm{NADP}^{+}$: nicotinamide adenine dinucleotide phosphate oxidized; NADPH: nicotinamide-adenine dinucleotide phosphate reduced; OXA: oxaloacetate; PEP: phosphoenolpyruvate; 6PG: 6-phosphogluconate; PPP: pentose phosphate pathway; PTS: phosphotransferase system; Rib5P: ribulose-5-phosphate; R5P: ribose5-phosphate; S7P: sedoheptulose-7-phosphate; TCA: tricarboxylic acid; X5P: xylulose-5-phosphate.

\section{Authors' contributions}

HK and KY carried out experiments and analyzed the primary data, and HK wrote the draft manuscript. $\mathrm{KH}$ and TH carried out metabolome analyses. $\mathrm{CO}$ and AK supervised all research and revised the manuscript. All authors read and approved the final manuscript.

\section{Author details}

${ }^{1}$ Graduate School of Science, Technology and Innovation, Kobe University, 1-1 Rokkodai, Nada, Kobe 657-8501, Japan. ${ }^{2}$ Department of Environmental and Life Sciences, School of Food and Nutritional Sciences, University of Shizuoka, 52-1 Yada, Suruga, Shizuoka 422-8526, Japan. ${ }^{3}$ Department of Chemical Science and Engineering, Graduate School of Engineering, Kobe University, 1-1 Rokkodai, Nada, Kobe 657-8501, Japan. ${ }^{4}$ Biomass Engineering Research Division, RIKEN, 1-7-22 Suehiro, Turumi, Yokohama, Kanagawa 230-0045, Japan.

\section{Acknowledgements}

We gratefully acknowledge Kaori Sei and Yoshimi Hori for technical assistance. We also thank Dr. Christopher John Vavricka Jr. (Kobe University) for critical reading of the manuscript.

\section{Competing interests}

The authors declare that they have no competing interests.

\section{Availability of data and materials}

All the data analyzed during this study have been included in this published article and Additional data.

\section{Consent for publication}

Not applicable.

\section{Ethics approval and consent for participate}

Not applicable.

\section{Funding}

This work was supported by Special Coordination Funds for Promoting Science and Technology, Creation of Innovation Centers for Advanced Interdisciplinary Research Areas (Innovative Bioproduction, Kobe) from the Ministry of Education, Culture, Sports, Science and Technology, Japan.

\section{Publisher's Note}

Springer Nature remains neutral with regard to jurisdictional claims in published maps and institutional affiliations.

Received: 4 March 2018 Accepted: 11 May 2018

Published online: 17 May 2018

\section{References}

1. Mosier N, Wyman C, Dale B, Elander R, Lee YY, Holtzapple M, et al. Features of promising technologies for pretreatment of lignocellulosic biomass. Bioresour Technol. 2005;96:673-86. https://doi.org/10.1016/j. biortech.2004.06.025.

2. Fehér A, Fehér C, Rozbach M, Barta Z. Combined approaches to xylose production from corn stover by dilute acid hydrolysis. Chem Biochem Eng Q. 2017;31:77-87. https://doi.org/10.15255/cabeq.2016.913.

3. Qureshi N, Saha BC, Dien B, Hector RE, Cotta MA. Production of butanol (a biofuel) from agricultural residues: part l—use of barley straw hydrolysate. Biomass Bioenergy. 2010;34:559-65. https://doi.org/10.1016/j. biombioe.2009.12.024.

4. Nigam JN. Hemicellulose acid hydrolysate to motor fuel ethanol by xylose-fermenting yeast. J Biotechnol. 2002;97:107-16. https://doi. org/10.1016/s0168-1656(02)00013-5.

5. Rao RS, Jyothi CP, Prakasham RS, Sarma PN, Rao LV. Xylitol production from corn fiber and sugarcane bagasse hydrolysates by Candida tropicalis. Bioresour Technol. 2006;97:1974-8. https://doi.org/10.1016/j.biort ech.2005.08.015.

6. Xiong H, von Weymarn N, Turunen O, Leisola M, Pastinen O. Xylanase production by Trichoderma reesei Rut C-30 grown on L-arabinose-rich plant hydrolysates. Bioresour Technol. 2005;96:753-9. https://doi.org/10.1016/j. biortech.2004.08.007.

7. Zhang G, Liu J, Kong II, Kwak S, Jin Y. Combining C6 and C5 sugar metabolism for enhancing microbial bioconversion. Curr Opin Chem Biol. 2015:29:49-57. https://doi.org/10.1016/j.cbpa.2015.09.008. 
8. David JD, Weismeyer H. Control of xylose metabolism in Escherichia coli. Biochim Biophys Acta. 1970;201:497-9. https://doi.org/10.1016/03044165(70)90171-90176

9. Ogden S, Haggerty D, Stoner CM, Kolodrubetz D, Schleif R. The Escherichia coli L-arabinose operon: binding sites of the regulatory proteins and a mechanism of positive and negative regulation. Proc Natl Acad Sci USA. 1980;77:3346-50. https://doi.org/10.1073/pnas.77.6.3346.

10. Daruwalla KR, Paxton AT, Henderson PJ. Energization of the transport systems for arabinose and comparison with galactose transport in Escherichia coli. Biochem J. 1981;200:611-27. https://doi.org/10.1042/ bj2000611.

11. Horazdovsky BF, Hogg RW. Genetic reconstitution of the high-affinity L-arabinose transport system. J Bacteriol. 1989;171:3053-9. https://doi. org/10.1128/jb.171.6.3053-3059.1989.

12. Deutscher J, Francke C, Postma PW. How phosphotransferase systemrelated protein phosphorylation regulates carbohydrate metabolism in bacteria. Microbiol Mol Biol Rev. 2006;70:939-1031. https://doi. org/10.1128/mmbr.00024-06.

13. Nichols NN, Dien BS, Bothast RJ. Use of catabolite repression mutants for fermentation of sugar mixtures to ethanol. Appl Microbiol Biotechnol. 2001;56:120-5. https://doi.org/10.1007/s002530100628.

14. Carmona SB, Moreno F, Bolívar F, Gosset G, Escalante A. Inactivation of the PTS as a strategy to engineer the production of aromatic metabolites in Escherichia coli. J Mol Microbiol Biotechnol. 2015;25:195-208. https://doi. org/10.1159/000380854.

15. Zhou Z, Wang C, Xu H, Chen Z, Cai H. Increasing succinic acid production using the PTS-independent glucose transport system in a Corynebacterium glutamicum PTS-defective mutant. J Ind Microbiol Biotechnol. 2015:42:1073-82. https://doi.org/10.1007/s10295-015-1630-9.

16. Flores N, Leal L, Sigala JC, de Anda R, Escalante A, Martínez A, et al. Growth recovery on glucose under aerobic conditions of an Escherichia coli strain carrying a phosphoenolpyruvate:carbohydrate phosphotransferase system deletion by inactivating arc $A$ and overexpressing the genes coding for glucokinase and galactose permease. J Mol Microbiol Biotechnol. 2007;13:105-16. https://doi.org/10.1159/000103602.

17. Kumagai H. History of modern biotechnology I. Berlin: Springer; 2000. https://doi.org/10.1007/3-540-44964-7.

18. Becker J, Wittmann C. Bio-based production of chemicals, materials and fuels-Corynebacterium glutamicum as versatile cell factory. Curr Opin Biotechnol. 2012;23:631-40. https://doi.org/10.1016/j.copbio.2011.11.012.

19. Wieschalka S, Blombach B, Bott M, Eikmanns BJ. Bio-based production of organic acids with Corynebacterium glutamicum. Microb Biotechnol. 2013;6:87-102. https://doi.org/10.1111/1751-7915.12013.

20. Collins MD, Cummins CS. Bergey's manual of systematic bacteriology. Boston: Springer; 2005. https://doi.org/10.1007/0-387-28021-9.

21. Kawaguchi H, Sasaki M, Vertes AA, Inui M, Yukawa H. Identification and functional analysis of the gene cluster for L-arabinose utilization in Corynebacterium glutamicum. Appl Environ Microbiol. 2009;75:3419-29. https://doi.org/10.1128/aem.02912-08.

22. Kawaguchi $H$, Sasaki M, Vertès AA, Inui M, Yukawa H. Engineering of an L-arabinose metabolic pathway in Corynebacterium glutamicum. Appl Microbiol Biotechnol. 2008;77:1053-62. https://doi.org/10.1007/s0025 $3-007-1244-x$

23. Kawaguchi $H$, Vertes AA, Okino S, Inui M, Yukawa H. Engineering of a xylose metabolic pathway in Corynebacterium glutamicum. Appl Environ Microbiol. 2006;72:3418-28. https://doi.org/10.1128/ aem.72.5.3418-3428.2006.

24. Meiswinkel TM, Gopinath V, Lindner SN, Nampoothiri KM, Wendisch VF. Accelerated pentose utilization by Corynebacterium glutamicum for accelerated production of lysine, glutamate, ornithine and putrescine. Microb Biotechnol. 2013;6:131-40. https://doi.org/10.1111/1751-7915.12001.

25. Schneider J, Niermann $K$, Wendisch VF. Production of the amino acids L-glutamate, $\mathrm{L}-\mathrm{lysine}, \mathrm{L}$-ornithine and $\mathrm{L}$-arginine from arabinose by recombinant Corynebacterium glutamicum. J Biotechnol. 2011;154:191-8. https ://doi.org/10.1016/j.jbiotec.2010.07.009.

26. Jo S, Yoon J, Lee S-M, Um Y, Han SO, Woo HM. Modular pathway engineering of Corynebacterium glutamicum to improve xylose utilization and succinate production. J Biotechnol. 2017;258:69-78. https://doi. org/10.1016/j.jbiotec.2017.01.015.

27. Jojima T, Noburyu R, Sasaki M, Tajima T, Suda M, Yukawa H, et al. Metabolic engineering for improved production of ethanol by Corynebacterium glutamicum. Appl Microbiol Biotechnol. 2015;99:1165-72. https://doi. org/10.1007/s00253-014-6223-4.

28. Chen T, Zhu N, Xia H. Aerobic production of succinate from arabinose by metabolically engineered Corynebacterium glutamicum. Bioresour Technol. 2014;151:411-4. https://doi.org/10.1016/j.biortech.2013.10.017.

29. Lange J, Müller F, Takors R, Blombach B. Harnessing novel chromosomal integration loci to utilize an organosolv-derived hemicellulose fraction for isobutanol production with engineered Corynebacterium glutamicum. Microb Biotechnol. 2018;11:257-63. https://doi.org/10.1111/17517915.12879.

30. Radek A, Krumbach K, Gätgens J, Wendisch VF, Wiechert W, Bott M, et al. Engineering of Corynebacterium glutamicum for minimized carbon loss during utilization of D-xylose containing substrates. J Biotechnol. 2014;192(Part A):156-60. https://doi.org/10.1016/j.jbiotec.2014.09.026.

31. Radek A, Müller M-F, Gätgens J, Eggeling L, Krumbach K, Marienhagen J, et al. Formation of xylitol and xylitol-5-phosphate and its impact on growth of D-xylose-utilizing Corynebacterium glutamicum strains. J Biotechnol. 2016;231:160-6. https://doi.org/10.1016/j.jbiotec.2016.06.009.

32. Radek A, Tenhaef N, Müller MF, Brüsseler C, Wiechert W, Marienhagen J, et al. Miniaturized and automated adaptive laboratory evolution: evolving Corynebacterium glutamicum towards an improved D-xylose utilization. Bioresour Technol. 2017;245:1377-85. https://doi.org/10.1016/j.biort ech.2017.05.055.

33. Gopinath V, Meiswinkel TM, Wendisch VF, Nampoothiri KM. Amino acid production from rice straw and wheat bran hydrolysates by recombinant pentose-utilizing Corynebacterium glutamicum. Appl Microbiol Biotechnol. 2011;92:985-96. https://doi.org/10.1007/s00253-011-3478-x.

34. Sasaki M, Jojima T, Kawaguchi H, Inui M, Yukawa H. Engineering of pentose transport in Corynebacterium glutamicum to improve simultaneous utilization of mixed sugars. Appl Microbiol Biotechnol. 2009;85:105-15. https://doi.org/10.1007/s00253-009-2065-x.

35. Kogure T, Kubota T, Suda M, Hiraga K, Inui M. Metabolic engineering of Corynebacterium glutamicum for shikimate overproduction by growth-arrested cell reaction. Metab Eng. 2016;38:204-16. https://doi. org/10.1016/.ymben.2016.08.005.

36. Lindner SN, Seibold GM, Henrich A, Krämer R, Wendisch VF. Phosphotransferase system-independent glucose utilization in Corynebacterium glutamicum by inositol permeases and glucokinases. Appl Environ Microbiol. 2011;77:3571-81. https://doi.org/10.1128/aem.02713-10.

37. Sambrook J, Russell DW. Molecular cloning: a laboratory manual. 3rd ed. New York: Cold Spring Harbor Laboratory Press; 2001.

38. Inui M, Murakami S, Okino S, Kawaguchi $H$, Vertès AA, Yukawa H. Metabolic analysis of Corynebacterium glutamicum during lactate and succinate productions under oxygen deprivation conditions. J Mol Microbiol Biotechnol. 2004;7:182-96. https://doi.org/10.1159/000079827.

39. Vertès AA, Inui M, Kobayashi M, Kurusu Y, Yukawa H. Presence of mrrand $\mathrm{mcr}$-like restriction systems in coryneform bacteria. Res Microbiol. 1993;144:181-5. https://doi.org/10.1016/0923-2508(93)90043-2.

40. Tateno T, Fukuda H, Kondo A. Direct production of L-lysine from raw corn starch by Corynebacterium glutamicum secreting Streptococcus bovis a-amylase using $\operatorname{csp} B$ promoter and signal sequence. Appl Microbiol Biotechnol. 2007;77:533-41. https://doi.org/10.1007/s00253-007-1191-6.

41. Tsuge Y, Kudou M, Kawaguchi H, Ishii J, Hasunuma T, Kondo A. FudC, a protein primarily responsible for furfural detoxification in Corynebacterium glutamicum. Appl Microbiol Biotechnol. 2016;100:2685-92. https:// doi.org/10.1007/s00253-015-7115-y.

42. Buescher JM, Moco S, Sauer U, Zamboni N. Ultrahigh performance liquid chromatography-tandem mass spectrometry method for fast and robust quantification of anionic and aromatic metabolites. Anal Chem. 2010;82:4403-12. https://doi.org/10.1021/ac100101d.

43. Kato H, Izumi Y, Hasunuma T, Matsuda F, Kondo A. Widely targeted metabolic profiling analysis of yeast central metabolites. J Biosci Bioeng. 2012;113:665-73. https://doi.org/10.1016/j.jbiosc.2011.12.013.

44. de Jonge LP, Douma RD, Heijnen JJ, van GulikWM. Optimization of cold methanol quenching for quantitative metabolomics of Penicillium chrysogenum. Metabolomics. 2012;8:727-35. https://doi.org/10.1007/s1130 6-011-0367-3.

45. Hasunuma T, Sanda T, Yamada R, Yoshimura K, Ishii J, Kondo A. Metabolic pathway engineering based on metabolomics confers acetic and formic acid tolerance to a recombinant xylose-fermenting strain 
of Saccharomyces cerevisiae. Microb Cell Fact. 2011;10:2. https://doi. org/10.1186/1475-2859-10-2.

46. Yamamoto S, Gunji W, Suzuki H, Toda H, Suda M, Jojima T, et al. Overexpression of genes encoding glycolytic enzymes in Corynebacterium glutamicum enhances glucose metabolism and alanine production under oxygen deprivation conditions. Appl Environ Microbiol. 2012;78:4447-57. https://doi.org/10.1128/aem.07998-11.

47. Hasegawa S, Tanaka Y, Suda M, Jojima T, Inui M. Enhanced glucose consumption and organic acid production by engineered Corynebacterium glutamicum based on analysis of a pfkB1 deletion mutant. Appl Environ Microbiol. 2017;83:e02638-16. https://doi.org/10.1128/aem.02638-16.

48. Limberg MH, Schulte J, Aryani T, Mahr R, Baumgart M, Bott M, et al. Metabolic profile of 1,5-diaminopentane producing Corynebacterium glutamicum under scale-down conditions: blueprint for robustness to bioreactor inhomogeneities. Biotechnol Bioeng. 2017;114:560-75. https ://doi.org/10.1002/bit.26184.

49. Matsuoka Y, Shimizu K. Catabolite regulation analysis of Escherichia coli for acetate overflow mechanism and co-consumption of multiple sugars based on systems biology approach using computer simulation. J Biotechnol. 2013;168:155-73. https://doi.org/10.1016/j.jbiotec.2013.06.023.

50. Wang C, Cai H, Zhou Z, Zhang K, Chen Z, Chen Y, et al. Investigation of pts $G$ gene in response to xylose utilization in Corynebacterium glutamicum. J Ind Microbiol Biotechnol. 2014;41:1249-58. https://doi. org/10.1007/s10295-014-1455-y.

51. Escalante A, Salinas Cervantes A, Gosset G, Bolívar F. Current knowledge of the Escherichia coli phosphoenolpyruvate-carbohydrate phosphotransferase system: peculiarities of regulation and impact on growth and product formation. Appl Microbiol Biotechnol. 2012;94:1483-94. https:// doi.org/10.1007/s00253-012-4101-5.

52. McCloskey D, Gangoiti JA, King ZA, Naviaux RK, Barshop BA, Palsson BO, et al. A model-driven quantitative metabolomics analysis of aerobic and anaerobic metabolism in E. coli K-12 MG1655 that is biochemically and thermodynamically consistent. Biotechnol Bioeng. 2014;111:803-15. https://doi.org/10.1002/bit.25133.

53. Gonzalez R, Tao H, Shanmugam KT, York SW, Ingram LO. Global gene expression differences associated with changes in glycolytic flux and growth rate in Escherichia coli during the fermentation of glucose and xylose. Biotechnol Prog. 2002;18:6-20. https://doi.org/10.1021/bp010 $121 \mathrm{i}$.
54. Tao H, Gonzalez R, Martinez A, Rodriguez M, Ingram LO, Preston JF, et al. Engineering a homo-ethanol pathway in Escherichia coli: increased glycolytic flux and levels of expression of glycolytic genes during xylose fermentation. J Bacteriol. 2001;183:2979-88. https://doi.org/10.1128/ jb.183.10.2979-2988.2001.

55. Reddy GK, Lindner SN, Wendisch VF. Metabolic engineering of an ATP-neutral Embden-Meyerhof-Parnas pathway in Corynebacterium glutamicum: growth restoration by an adaptive point mutation in NADH dehydrogenase. Appl Environ Microbiol. 2015;81:1996-2005. https://doi. org/10.1128/aem.03116-14.

56. Noack S, Voges R, Gätgens J, Wiechert W. The linkage between nutrient supply, intracellular enzyme abundances and bacterial growth: new evidences from the central carbon metabolism of Corynebacterium glutamicum. J Biotechnol. 2017;258:13-24. https://doi.org/10.1016/j.jbiot ec.2017.06.407.

57. Radoš D, Turner DL, Fonseca LL, Carvalho AL, Blombach B, Eikmanns BJ, et al. Carbon flux analysis by ${ }^{13} \mathrm{C}$ nuclear magnetic resonance to determine the effect of $\mathrm{CO}_{2}$ on anaerobic succinate production by Corynebacterium glutamicum. Appl Environ Microbiol. 2014;80:3015-24. https://doi. org/10.1128/aem.04189-13.

58. Schulte J, Baumgart M, Bott M. Identification of the CAMP phosphodiesterase CpdA as novel key player in CAMP-dependent regulation in Corynebacterium glutamicum. Mol Microbiol. 2017;103:534-52. https:// doi.org/10.1111/mmi.13574.

59. Chen Z, Bommareddy RR, Frank D, Rappert S, Zeng AP. Deregulation of feedback inhibition of phosphoenolpyruvate carboxylase for improved lysine production in Corynebacterium glutamicum. Appl Environ Microbiol. 2014;80:1388-93. https://doi.org/10.1128/aem.03535-13.

60. van Ooyen J, Noack S, Bott M, Reth A, Eggeling L. Improved L-lysine production with Corynebacterium glutamicum and systemic insight into citrate synthase flux and activity. Biotechnol Bioeng. 2012;109:2070-81. https://doi.org/10.1002/bit.24486.

61. Underwood SA, Buszko ML, Shanmugam KT, Ingram LO. Flux through citrate synthase limits the growth of ethanologenic Escherichia coli KO1 1 during xylose fermentation. Appl Environ Microbiol. 2002;68:1071-81. https://doi.org/10.1128/aem.68.3.1071-1081.2002.
Ready to submit your research? Choose BMC and benefit from:

- fast, convenient online submission

- thorough peer review by experienced researchers in your field

- rapid publication on acceptance

- support for research data, including large and complex data types

- gold Open Access which fosters wider collaboration and increased citations

- maximum visibility for your research: over 100M website views per year

At BMC, research is always in progress.

Learn more biomedcentral.com/submissions 